\section{Antimicrobial Sterile Gloves Reduce Pathogen Transmission in an In Vitro Glove Perforation Model}

To the Editor-Surgical gloves act as a barrier to the bidirectional transmission of pathogens between surgeon and patient. ${ }^{1}$ Nevertheless, glove defects are common and increase with the duration of glove wear. ${ }^{2,3}$ Preoperative surgical hand disinfection may well reduce the risk of germ transmission in the event of a glove breach. However, original levels of skin flora can be re-established during surgery. ${ }^{4,5}$ Therefore, we analyzed the ability of a novel antimicrobial surgical glove to disinfect contaminated glove fluid passing through a hole in the glove in vitro.

The bacteria used in our study included a methicillinsusceptible strain of Staphylococcus aureus (ATCC 29213 [American Type Culture Collection, Manassas, VA]), Klebsiella oxytoca (ATCC 700324), Escherichia coli (ATCC 25922), Enterococcus faecium (ATCC 6057), and Staphylococcus epidermidis (ATCC 12228). Five contaminated solutions were prepared to simulate glove fluid; each contained 1 of the aforementioned pathogens. All strains were recovered from frozen stock. After determination of purity, enrichment broth was cultured overnight and adjusted to a concentration of approximately $10^{5}$ colony-forming units (CFU)/mL.

Two different surgical gloves were tested: an antimicrobial trilayer glove containing liquid droplets of antiseptic (G-Bact, Hutchinson-Santé, SNC, Paris, France) in its core and a conventional sterile glove of the same thickness (G-Derm, Hutchinson-Santé) as a control. The test conditions were designed to simulate an injury resulting from the penetration of a sharp instrument with high reproducibility. The test site consisted of a chamber supporting a mount for the finger of the glove tested. In-glove pressure was regulated by a barometer controlling the volume of fluid transmitted, the velocity of passage (ie, time of contact with the antimicrobial layer), and the stretch of the glove. The sample gloves were prepared by separating the fingers with a sterile knife, filling them with the simulated glove fluid, and affixing them to the mount. Care was taken to maintain the sterility of the external surface of the glove finger. After manual perforation using a 20-gauge needle (Microlance 3, Becton Dickinson, Heidelberg, Germany), $5 \mu \mathrm{L}$ of the passed fluid was collected for examination.

The samples were processed immediately. Each was vortexed for 30 seconds in $3 \mathrm{~mL}$ of sterile saline $(0.9 \%)$ diluted with inhibitor ([NaClPeptone + LTHTh, Haipha $\mathrm{GmbH}$, Eppelheim, Germany]; the appropriate concentration was determined in prior experiments (data not shown). Next, $100 \mu \mathrm{L}$ of the suspension was streaked onto Columbia agar (5\% sheep blood; Oxoid, Wedel, Germany) and incubated for 48 hours at $36^{\circ} \mathrm{C}$. Colonies were counted and differentiated using the VITEK 2 Compact system (Biomérieux Deutschland
GmbH, Nürtingen, Germany). Microbial growth was measured in CFUs. Each experiment was repeated 6 times with 6 replications. The mean reduction factors (RFs) were calculated for the different sample gloves and pathogens as follows: $\mathrm{RF}=$ $\log$ (total CFUs before passage) - $\log$ (total CFUs after passage).

The mean $\mathrm{RF}_{\text {[G-Bact] }}$ results were as follows: against methicillin-susceptible $S$. aureus, $\mathrm{RF}_{[\mathrm{G}-\mathrm{Bact}]}=4.22$; against E. coli, $\mathrm{RF}_{[\mathrm{G}-\mathrm{Bact}]}=1.58$; against E. faecium, $\mathrm{RF}_{[\mathrm{G}-\mathrm{Bact}]}=3.56$; against $K$. oxytoca, $\mathrm{RF}_{\text {[G-Bact] }}=3.68$; and against $S$. epidermidis, $\mathrm{RF}_{[\mathrm{G}-\mathrm{Bact}]}=3.40$. Conventional sterile gloves resulted in lower RFs; the mean $\mathrm{RF}_{\text {[G-Derm] }}$ results were as follows: 0.2 against S. aureus, $\mathrm{RF}_{[\mathrm{G}-\mathrm{Derm}]}=0.2$; against $E$. coli, $\mathrm{RF}_{[\mathrm{G}-\mathrm{Derm}]}=0.33$; against E. faecium, $\mathrm{RF}_{[\mathrm{G}-\mathrm{Derm}]}=0.04$; against $K$. oxytoca, $\mathrm{RF}_{[\mathrm{G}-\mathrm{Derm}]}=0.01$; and against $S$. epidermidis, $\mathrm{RF}_{[\mathrm{G}-\mathrm{Derm}]}=0.04$. The mean reduction factors against all species $\left(\mathrm{RF}_{[\mathrm{All}]}\right)$ were $\mathrm{RF}_{[\mathrm{All}]}=3.29$ for G-Bact and $\mathrm{RF}_{[\mathrm{All}]}=0.1$ for G-Derm. Thus, G-Bact was more antibacterially efficaceous.

The skin flora of the surgical team members were identified as a possible source of surgical site infection (SSI), mainly in the case of glove breach. ${ }^{1-3,6}$ Misteli et $\mathrm{al}^{7}$ identified "perforation of surgical glove" as a risk factor for SSI when a single antibiotic shot was not administered. Therefore, antimicrobial surgical gloves may be useful to overcome the risk of glove perforation.

However, it must be emphasized that several antimicrobial gloves using different techniques and based on different concepts are currently being examined. Assadian et $\mathrm{al}^{8}$ examined a sterile surgical glove featuring a chlorhexidine-coated inner surface and reported significant suppression of surgeon hand flora. This study design targeted inadequate hand hygiene and bacterial regrowth. Examination gloves with external antimicrobial coating are being tested in experimental settings and focus on preventing transmission of pathogens via the outer surface (not yet available as certified medical products). ${ }^{9}$ Prevention of bloodborne viral infections due to sharp instrument injuries is the aim of another antiviral trilayer glove (G-Vir, HutchinsonSanté) that has also shown reduced transmission of bacteria. ${ }^{1,10}$

In the present experiment, we demonstrated that the G-Bact antimicrobial surgical glove disinfected glove fluid in a simulated glove breach in vitro. Thus, its use may prevent bacterial contamination of the surgical site under real surgical conditions and may increase patient safety. However, this can only be confirmed by clinical studies of sufficient power with SSI as the direct endpoint.

1. Concurrent transmission of pathogens in cases of glove breach can highly probably be reduced by an antimicrobial glove technology at the site of perforation.

2. The ideal antimicrobial glove protects its wearer from bloodborne infections via antiviral efficacy and protects the patient from surgical site contamination via suppression of the bacterial flora from surgeons' hands or reduction of pathogen passage. The ideal antimicrobial glove prevents externally contaminated gloves from functioning as vectors of pathogenic transmission from one location to another. 


\section{A C KNOW LEDGMENTS}

Financial support: No financial support was provided relevant to this article. Potential conflicts of interest: All authors and coauthors deny any potential conflict of interest (eg, employment, consulting fees, research contracts, stock ownership, patent licenses, honoraria, advisory affiliations, etc.).

Matthias Napp, MD; ${ }^{1}$ Georg Daeschlein, MD; Sebastian von Podewils, MA; ${ }^{2}$ Romy Spitzmueller, Dipl. Ing.; ${ }^{2}$ Denis Guembel, MD; ${ }^{1,3}$ Michael Juenger, $\mathrm{MD}^{2}$ Peter Hinz, $\mathrm{MD}^{1}$

Affiliations: 1. Department of Trauma and Orthopedic Surgery, Clinic of Surgery, Ernst Moritz Arndt University, Sauerbruchstrasse, 17489 Greifswald, Germany; 2. Clinic of Dermatology, Ernst Moritz Arndt University, Sauerbruchstrasse, 17489 Greifswald, Germany; 3. Emergency Hospital Berlin (ukb), Warener Straße 7, 12683 Berlin, Germany

Address correspondence to Georg Daeschlein, MD, Clinic of Dermatology, Ernst Moritz Arndt University, Sauerbruchstrasse, 17489 Greifswald, Germany (georg.daeschlein@uni-greifswald.de).

Infect. Control Hosp. Epidemiol. 2015;36(10):1249-1250

(c) 2015 by The Society for Healthcare Epidemiology of America. All rights reserved. 0899-823X/2015/3610-0021. DOI: 10.1017/ice.2015.164

\section{REFERENCES}

1. Daeschlein G, Kramer A, Arnold A, et al. Evaluation of an innovative antimicrobial surgical glove technology to reduce the risk of microbial passage following intraoperative perforation. Am J Infect Control 2011;39:98-103.

2. Kojima Y, Ohashi M. Unnoticed glove perforation during thoracoscopic and open thoracic surgery. Ann Thorac Surg 2005;80:1078-1080.

3. Partecke LI, Goerdt AM, Langer I, et al. Incidence of microperforation for surgical gloves depends on the duration of wear. Infect. Control Hosp. Epidemiol. 2009;30:409-414.

4. Peterson AF, Rosenberg A, Alatary SD. Comparative evaluation of surgical scrub preparations. Surg Gynecol Obstet 1978;146:63-65.

5. Rotter ML, Kampf G, Suchomel M, et al. Population kinetics of the skin flora on gloved hands following surgical hand disinfection within 3 propanol-based hand rubs: a prospective, randomized, double-blinded trial. Infect Control Hosp Epidemiol 2007;28:346-350.

6. Harnoss JC, Partecke LI, Heidecke CD, et al. Concentration of bacteria passing through puncture holes in surgical gloves. Am J Infect Control 2010;38:154-158.

7. Misteli H, Weber WP, Reck S, et al. Surgical glove perforation and the risk of surgical site infection. Arch Surg 2009;144:553-558.

8. Assadian O, Kramer A, Ouriel K, et al. Suppression of surgeon's bacterial hand flora during surgical procedures with a new antimicrobial surgical glove. Surg Infect (Larchmt.) 2014;15:43-49.

9. Leitgeb J, Schuster R, Eng AH, et al. In-vitro experimental evaluation of skin-to-surface recovery of four bacterial species by antibacterial and non-antibacterial medical examination gloves. Antimicrob Resist Infect Control 2013;2:27.

10. Edmiston CE Jr, Zhou SS, Hoerner P, et al. Evaluation of an antimicrobial surgical glove to inactivate live human immunodeficiency virus following simulated glove puncture. Surgery 2013;153:225-233.

\section{A Small Outbreak of Food Poisoning Among Attendees of a Public Health Thesis Examination Conference}

To the Editor-Food poisoning is an important gastrointestinal problem and outbreaks are commonly reported. However, outbreaks of food poisoning in medical centers are rarely reported. ${ }^{1-3}$ For example, Chávez-de la Peña et $\mathrm{al}^{2}$ and Metz et $\mathrm{al}^{3}$ reported outbreaks of Salmonella gastroenteritis among hospital staff. One interesting situation involves outbreaks that occur during medical school conferences. ${ }^{1}$ Herein, the authors report a small outbreak of food poisoning that occurred among attendees of a public health thesis examination conference. During the 6-hour examination, several deserts were served to the attendees. After the conference, a medical professor and a student developed acute symptoms of food poisoning. The professor had more severe symptoms with many episodes of diarrhea and vomiting. A previous report by Vinnard et $\mathrm{al}^{1}$ detailed a similar outbreak among medical conference attendees. Vinnard et $\mathrm{al}^{1}$ found "multiple food source contamination as the source of the outbreak."1(p73) In the present case, the exact microbiologic cause of contamination could not be determined because no samples of the contaminated food were available for study. Indeed, most medical centers and hospitals prepare their own food, so adherence to food cleanness and safety standards is expected. However, during a conference, food is typically catered from outside sources and contamination is possible. ${ }^{3}$

\section{ACKNOWLEDGMENTS}

Financial support. None reported.

Potential conflicts of interest. Both authors report no conflicts of interest relevant to this article.

Wasana Kaewla, PhD; Viroj Wiwanitkit, MD

Affiliations: Public Health Curriculum, Surin Rajabhat University, Surin, Thailand.

Address correspondence to Wasana Kaewla, Public Health Curriculum, Surin Rajabhat University, Surin, Thailand (wasanak3@hotmail.com). Infect. Control Hosp. Epidemiol. 2015;36(10):1250

(C) 2015 by The Society for Healthcare Epidemiology of America. All rights reserved. 0899-823X/2015/3610-0022. DOI: 10.1017/ice.2015.162

\section{REFERENCES}

1. Vinnard C, Lee I, Linkin D. Successful control of a norovirus outbreak among attendees of a hospital teaching conference. Am J Infect Control 2012;40:73-74.

2. Chávez-de la Peña ME, Higuera-Iglesias AL, Huertas-Jiménez MA, et al. An outbreak of Salmonella gastroenteritis among hospital workers. Salud Publica Mex 2001;43:211-216.

3. Metz R, Jahn B, Kohnen W, Viertel A, Jansen B. Outbreak of Salmonella enteritidis gastrointestinal infections among medical staff due to contaminated food prepared outside the hospital. J Hosp Infect 2001;48:324-325. 